\title{
Indoor Air Quality in Museum Display Cases: Volatile Emissions, Materials Contributions, Impacts
}

\author{
Oscar Chiantore *(D) and Tommaso Poli \\ Department of Chemistry, University of Torino, Via Pietro Giuria 7, 10125 Torino, Italy; tommaso.poli@unito.it \\ * Correspondence: oscar.chiantore@unito.it
}

\begin{abstract}
The control of air quality in museum showcases is a growing issue for the conservation of the displayed artefacts. Inside an airtight showcase, volatile substances may rapidly concentrate and favor or directly cause the degradation or other unwanted phenomena on the objects. The role of materials used in the construction of museum display cases as a source of pollutants and volatile compounds dangerous for the cultural heritage integrity is here reviewed with an illustration of consequences and critical damages. Ways of assessing the suitability of materials used either in the construction or in use of the display cases are also discussed altogether with an overview of the possible choices for monitoring the air quality and limiting the concentration of volatile compounds in their interior.
\end{abstract}

Keywords: display cases; indoor air quality; volatile organic compounds; pollutants; emissions; preventive conservation; heritage science

Citation: Chiantore, O.; Poli, T. Indoor Air Quality in Museum Display Cases: Volatile Emissions, Materials Contributions, Impacts. Atmosphere 2021, 12, 364. https:// doi.org/10.3390/atmos12030364

Academic Editor:

Liudmila Golobokova

Received: 28 January 2021

Accepted: 5 March 2021

Published: 10 March 2021

Publisher's Note: MDPI stays neutral with regard to jurisdictional claims in published maps and institutional affiliations.

Copyright: (c) 2021 by the authors. Licensee MDPI, Basel, Switzerland. This article is an open access article distributed under the terms and conditions of the Creative Commons Attribution (CC BY) license (https:/ / creativecommons.org/licenses/by/ $4.0 /)$.

\section{Introduction}

The quality of air in the museum environment is of primary importance in determining conditions appropriate for the collections conservation. It is widely acknowledged that in museum, galleries, and archives, the building materials, furnishings, and technical equipment can act as important sources of chemical emissions capable of interacting with the works of art inside [1,2]. Materials, either traditional or modern, may act as a source of indoor pollutants, and this fact with all related consequences has been recognized for a while in the museum environment [3].

The interactions between chemical compounds conveyed in air and the artwork materials may take place in different ways, more generally through reactions eventually fostered by the temperature and relative humidity conditions, together with the contribution of dust and pollutants interactions finally show up in the form of disfiguring effects on the surfaces and of materials degradation.

In museums, specific and more demanding situations are represented by containers such as storage boxes, cabinets, drawers, and display cases, where the emission of volatile chemical compounds from constituent materials may seriously harm the items therein sheltered. In all of the above enclosures, the air exchange rate is more or less severely restricted with the consequence that compounds that originated from the local emissions will easily accumulate in the close environment until reaching concentrations capable of inducing damages to the objects. Current museum guidelines consider that well-designed display cases are not only intended to provide an object's visibility and physical protection, but they are indeed the tools for the primary environmental control of the objects [4]. High-performance display cases must exclude the ingress of dust, pollutants, and insects and form a buffer to ambient temperature and relative humidity changes. They are classified according to their air exchange rates: low rates of exchange allow for high relative humidity stability against reasonable temperature changes and therefore reduced amounts of humidity buffer and pollutant adsorbents become necessary, making in such a way the maintenance more affordable $[5,6]$. 
Museum display cases are labeled conservation grade when they guarantee 0.1 , or less, air change per day. With such air tightness values, gases and pollutants originated by the construction materials of the display case may become a problem when their concentration builds up and reaches values dangerous for the exposed objects. When items to exhibit are less demanding, i.e., more chemically inert or for temporary exhibitions, display cases with air exchange rates of 0.25 or 1 day $^{-1}$ are also employed. One advantage of showcases without absolute air tightness is that volatile products emitted can disperse on the outside [5]. From the preventive conservation point, whether it is more advisable to have museum display cases completely sealed or leaky is still a question of debate among conservators, scientists, and curators-without even considering what can be the contribution of products offgassed by the objects themselves.

In the present paper, the nature and quality of volatile compounds emitted from materials used in the manufacturing and finishing of museum display cases is discussed in regard to the harms that can be brought to the heritage objects. In the context of our interest, we have to deal with true pollutants, which are compounds known to induce damages on cultural materials, and compounds whose effects should still be verified. From the chemical point of view, the volatile compounds emitted from display case materials and other museum containers are mostly of organic nature and conventionally grouped as volatile organic compounds (VOCs) [3,7]. VOCs are also sub-categorized by the ease they are emitted according to their boiling points at standard atmospheric pressure of $1 \mathrm{~atm}$. Hence, very volatile organic compounds (VVOCs) are those with boiling points $<10{ }^{\circ} \mathrm{C}$, volatile organic compounds (VOCs) are those having boiling points $\leq 250^{\circ} \mathrm{C}$, and semi-volatile organic compounds (SVOCs) are those with boiling points $>250{ }^{\circ} \mathrm{C}$, up to $380-400{ }^{\circ} \mathrm{C}$ [8]. All these compounds either are already present in the materials as residues from production reactions and processes, as feedstocks impurities, as additives and formulation components, or else they are the result of chemical reactions such as oxidations and other degradation processes.

The paper is organized in sections that discuss the volatile emissions from display cases and museum enclosures with a focus on the pollutant effects and the provenance materials, the pollutant levels for artifacts deterioration, the evaluation of emissions from display case constituent materials, and the viable solutions for the control and removal of emissions.

\section{Effects of Volatile Emissions in Display Cases and in Other Museum Enclosures}

A variety of detrimental effects may occur on objects, from the corrosion of metals to stone deterioration to the degradation of organic materials, depending on the type of VOC and the susceptibility of material types; in some cases, a merely aesthetical damage is produced that is not directly harmful for the object but nevertheless making it necessary to open the show case and undertake a cleaning operation. The most common visible appearances on museum objects and surfaces are efflorescences, salt crystallizations, and hazes.

Crystalline efflorescences on shells in museum collections were found to be mixed acetate/formate salts. The acetic and formic acid vapors derived from wooden storage cabinets with hardwoods, particularly oak, emit the highest concentrations [9]. The production of formic acid from wood is generally much lower than that of acetic acid, and its source is less well understood. It might come from the hydrolysis of formyl groups in hemicelluloses, although a more important route is attributed to the oxidation of wooden originated formaldehyde. Formaldehyde in wood is formed to different extents from cellulose, hemicelluloses, and lignin components depending on the moisture conditions, temperature treatments, and processing procedures [10].

The role of acetic acid as a corrosion agent against many different types of materials in museums has been broadly investigated. Typical examples are acetate efflorescences found on bronze antiquities, lead artifacts, and copper alloys stored in wooden cabinets [11-14]. 
The acetic acid emissions could be attributed not only to the wood but also to the adhesives and varnishes used to fabricate the cabinets.

Several different acetate salts have been frequently observed as efflorescences on calcareous objects stored in museum cabinets and display cases: not only pure calcium acetate, but mixed salts where the acetate forms phases with calcium chloride and nitrate in different hydrated forms [15,16]. Similar crystals of hydrated calcium acetate-chloride were identified on Greek ceramics stored in cherrywood display cases [17]. On porous calcareous objects, the chloride presence is due to the archaeological burial environments from which the objects originate.

In a museum collection, dramatic efflorescences and damages were observed on lead and tin glazed ceramic tiles of various origins and dates [18]. Analysis of the salts revealed the presence of a complex calcium acetate-chloride-nitrate hydrated structure formed on the surface of the tiles after reaction with acetic acid vapors from the storage environment. The concentrations of gaseous pollutants were measured in several display cases and halls of the museum, and in the cases, they were fairly high. From the efflorescence compositions, it could be concluded that they were formed as result of the interaction between the acetic acid vapor from the wooden storage and the salt contamination, chlorides, and nitrates, which are usually present in the tiles $[19,20]$.

Other types of efflorescence salts on calcareous historic objects stored in wood cabinets have been also described. White crystals were collected from four different objects in three museums under different environmental conditions (relative humidity, temperature, furniture, etc.) [21]. On ancient archaeological ceramics and on a copper alloy bowl, formate mixed salts were present in addition to acetates. On objects stored under different conditions, a white needle-like salt was identified as hydrated calcium acetate-formatenitrate. Although hard- and softwoods emit 3 to 10 times more acetic acid than formic acid, the crystal backbone structure was found to be based on formate ions. It was concluded that aggression by formic acid happens to a much larger extent than by acetic acid as a consequence of the higher strength of formic acid [22].

Corrosion effects produced by wood acidic emissions in museum collections have been well documented also on metal objects [23]. The active corrosion of metals, in particular lead and lead-containing alloys, takes place in the indoor environment of museums with acetic acid as prevalent pollutant. Wood is not the only source because adhesives, coatings, and sealants can be acetic acid emitters. Acetate solvents are most commonly employed in paints, and if they undergo hydrolytic degradation, acetic acid is formed. The corrosion potential of acetic acid against metals is strongly enhanced by high relative humidity values, but even under the controlled conditions of museum rooms and display cases, the corrosion of copper and lead-based metals is seen to proceed steadily [24].

The effects of museum environment and particularly of storage and display materials on metal coins have been also described [25]. Shocking disfigurations were detected in coins confined in the close spaces of showcases and cabinet drawers without ventilation. The parts emitting harmful gases were not only wood used in the construction of cases and furniture but also textiles, paints, adhesives, carboard varnishes, and different lining or flooring materials. In addition to the acidic emissions from wood and paints or adhesives, an important contribution to the coin damages was given by sulfur, which is known to be emitted in the form of hydrogen sulfide by wool and other proteinaceous materials. In its reduced form of sulfides, sulfur is one of the most problematic pollutants to attack metals in museum and collection environments. Minute amounts of sulfur can cause significant visual and physical effects on metal surfaces, and particularly on silver. Hydrogen sulfide reacts with silver to form a surface film of silver sulfide, and the same will happen on copper. Sources of sulfur in museums reside in wool fabrics from historical collections and in finishing or decoration parts made with vulcanized rubber such as floor coverings or carpet backing. Moreover, with the development and diffusion of plastic materials and synthetic dyes, the presence of chemical compounds containing sulfur has increased 
substantially in the recent years because of their use in dye structures and additives for polymer stabilization [26].

The formation of dark films on silver objects when they are exposed to polluted atmosphere is said to tarnish, and the principal component of a tarnish film is silver sulfide [27]. Tarnish is aesthetically displeasing, and the thin corrosion layers can be removed in different ways, but in the sealed environment of display cases, the accumulation of high levels of aggressive gases produces on silver objects more severe irrecoverable damages. Lacquered silver Tibetan artifacts after being stored for more than 20 years in well-closed display cases were found to be affected by two types of severe corrosion: the predominant one was in the form of thick layers of black silver sulfide crystals growing as whiskers perpendicular to the surface; a second type of corrosion was in the form of black fine filaments growing parallel to the surface [28]. Evaluation of the environment in the display cases revealed fairly high concentrations of tarnishing gases, which were much higher than the levels in the open spaces of the museum. In the display cases, polyisoprene rubber carpet backing and carpet wood fibers were the source of hydrogen sulfide causing the corrosion. The two different crystallization forms of the corrosion were attributed to the fact that the objects were lacquered and the silver was exposed to the tarnishing gases only where lacquer was missing, with the formation of whiskers, or where breaks occurred in the film coating with the filiform corrosion taking place underneath the coating.

Glass objects may be also affected by gaseous emissions in the museum environment. The conservation of glass collections strongly depends on climate, being particularly sensitive to large fluctuations in relative humidity $(\mathrm{RH})$. According to the different compositions of glass, deterioration appears as droplets or moisture films or efflorescences on the surfaces [29]. Ions sampled on the surface of glass vessels from different museums revealed, among others, the presence of acetate and formate anions, which are attributed to the emission of formic acid, acetic acid, and formaldehyde from the wood or wood composite materials used in storage or display [30].

As a consequence of all the collected evidences, conservation guidelines for museums and exhibitions are nowadays fully recognizing that careful control of the atmosphere in the storage and exhibition room is essential for the conservation of different types of historic objects [3,4]. Modern guidelines of preventive conservation ban the use of wood for the permanent storage and display of objects in order to avoid efflorescence salts crystallization, corrosion on surfaces, and other damages to the artefacts. As a result of the aesthetic qualities of wood, the above caveat is not always fulfilled, particularly when in museums, the final decision for presentation of objects in galleries and display cases is made without the professional conservators approval. When wooden parts in storage boxes or display cases cannot be avoided, it has been suggested that to prevent the release of volatiles, the wood surfaces should be sealed with a coating. The main problem here is the choice of wood sealant, which not only must provide a barrier to the volatiles but must itself be free of dangerous emissions. A study on wood coatings for display and storage cases showed that most of the coatings are not able to make the wood completely safe, and maximum attention must be paid to the coating emissions and the safety time necessary for drying or curing [31].

There is worldwide recognition in museums and among the professional conservators that display cases must be built with chemically stable materials, which primarily means avoiding the use of wood and wood composites [4,6,32]. The structure of nowadays conservation grade display cases is essentially made of glass panels and metal sheets, but for the whole construction, many organic materials are involved as well under the form of paints, adhesives, gaskets, or insulators, and in recent years, it became clear that new sources and new forms of degradation and of disturbing effects on art objects were caused by the modern constructions.

The phenomena of extensive visual disturbance were detected on glasses of display cases that are fairly new in construction in different museum environments [33]. These appearances are named haze or fog from the type of pattern and form they have. It was 
natural at first to think that pollutants from the case materials or from the objects on display could be the cause of the glass fogging, but it was as well considered that glass is not completely chemically inert, and the type or treatment of glass may have effects. A detailed study of the fogging on glass display cases was performed on new galleries of Royal Ontario Museum, in Toronto, when more than 2000 glass panels from display cases showed some haze [34]. Fogging residues were fully characterized in order to determine their source and propose an effective cleaning protocol. The residues showed a surprising abundance of compounds, from sodium salts of inorganic and organic acids to n-alkane hydrocarbons, ketones (both long-chain and alkyl phenyl), long-chain nitriles, silicones, and phthalates. Synthetic polymers and polymer additives were also identified. Some of the fogging components were deposited from the air in the museum, whereas the sodium salts of formic, lactic, and fatty acids were attributed to reactions of available sodium with the volatile acids condensed on glass. Most of the glass residues contained n-alkane hydrocarbons, which, being more or less abundant in different glass batches, were attributed to manufacturing lubricants or release agents from production and finishing machinery. In the display cases, laminated glass is generally employed, which is formed by different glass layers heated and pressed for adhering to polyvinyl butyral or ethylenevinyl acetate film. During the production process, the glass sheets come into contact with vacuum suction cup glass lifters, conveyor belts, and shipping supports, all of them using lubricants. It was concluded that part of the lubricants remained from manufacturing processes and were not removed by previous cleaning operations. The problem of effective cleaning then came to the fore, with the possibility that some residue on the panels (glycols, acids, surfactant components, antifoaming, etc.) could originate from glass cleaners and polishes. Thorough cleaning of the glass appeared necessary to remove all greasy residues, and a new cleaning protocol was developed and validated for museum applications.

The formation of hazy films on glass surfaces has long been known in the conservation field, particularly with framed oil paintings, which occasionally show so-called ghost images on the inside of the protective glasses. A scientific study of ghost images revealed that they were generated by mixtures of free fatty acids evaporating from the oil binders and condensing on the glass interiors [35]. Palmitic and stearic acids were the main evaporating components, and the hazing intensity could be attributed to the binder nature with slow-drying paint formulations, which are richer in free fatty acids, producing more intense ghost images. Haziness from free fatty acid deposits in museums has been seen not only on protective glasses but also on the surfaces of many types of artworks dating from the late 19th through 20th centuries, going from paintings to sculptures or works on paper [36]. With the evolution of artistic techniques, the introduction of new materials and the countless formulation changes experimented by the artists, the sources of fatty acids in artworks are greater than could be expected. In addition to the variety of oil binders having different compositions, other relevant sources are alkyd paints, beeswax coating formulations, pigment extenders, and surface-active coatings such as stearate salts. As fogging patterns and ghost images are immediate visible evidence of fatty acids deposition on the glass enclosures of paintings, it is obvious to expect that in the presence of emitters, the same acids can deposit to some extent on glass surfaces within display cases. Measurements done on samples wiped from the glass interior of an enclosure containing wooden and metal objects at the Viking ship museum in Oslo indeed confirmed the presence of fatty acids, together with formic and acetic acid [37]. Interestingly enough is the fact than in the deposited films, more than 30 volatile organic compounds were present.

In recent years, other types of fogging on glass and efflorescences on different exposed surfaces were discovered in the interior of modern and newly built cases [38]. As no wooden material was involved, and in many cases, neither was there interaction with objects on display, it became necessary to consider an unexpected contribution from some of the construction materials, all of them previously tested and approved for not giving acidic emissions. Checks on the materials and analysis performed by museum and conservation labs led to the conclusion that the efflorescences were derived from 
the reaction of a volatile organic amine, a substitute piperidinol compound, with acidic molecules present in the closed environment $[38,39]$. In particular, in empty display cases or in cases containing objects without interacting materials, crystalline efflorescences were seen to grow on gaskets as a result of the reaction of the above-mentioned amine with a dichlorobenzoic acid present as a by-product of the curing process of peroxide-cured silicone elastomers. Efflorescence on the objects, on the other hand, was the result of the volatile amine deposition and subsequent reaction with some acid component on the surfaces. The organic amine was identified as a molecular fragment coming from an hindered amine light stabilizer (HALS) added to the adhesive used to bond the glass and metal of the display cases. Its high reactivity against acidic compounds was confirmed with laboratory experiments where different types of crystal salts could be obtained in close environments simulating the display case condition [39].

The above findings are bringing into the conservation community much more understanding of the problems that are to be faced with the introduction in galleries and museums of new materials whose production generally involves complex and undetermined formulations containing additives, stabilizers, pigments, and fillers. Experience has shown that not only the corrosion effects from acidic compounds must be considered, but also damaging reactions from unusual organic bases. The standard tests normally used by museums for the approval of materials are not effective, as they do not cover all the phenomena that can possibly occur. This becomes especially true with the widespread recommended use of airtight enclosures where the concentration of emissions can increase up to critical threshold reaction values.

\section{Old and New Indoor Pollutants in Display Cases}

In the museum environment, the most important dangerous compounds are retained formic and acetic acids, both inducing corrosion on metals, on calcareous and on cellulosic materials. A comparison between formic and acetic acid concentrations determined outdoor and indoor in a museum revealed that through all the year, the values were much higher inside the showcases [40]. As the organic acids are emitted by internal sources (construction materials, furniture), the first guideline for the better preservation of museum collections must be to store artworks in drawers, cabinets, or display cases made without wooden parts.

Formaldehyde in wood is present in quite low amounts, depending on boundary conditions, but formaldehyde emissions can be abundant from wood composites (particleboard, fiberboard), coming primarily from the urea-formaldehyde adhesive used in the panels production [41]. Formaldehyde became a quite ubiquitous compound in indoor environments as it started to be employed in the synthesis of many types resins, coatings, and insulating materials of common use in construction, furniture, and decoration fields. Its relevance for the indoor air quality in museums and the damages to works of art was for the first time described in a seminal report of research made at the Center for Conservation and Technical Studies, Harvard University Art Museums [42]. Formaldehyde emitted by resins oxidizes to formic acid, which is the effective damaging compound. It should be mentioned that the control of formaldehyde emissions from products should be very strict, as formaldehyde has been declared a probable human carcinogen by national and international health organizations which indicated maximum allowed levels of emissions [43]. Due to the aesthetic appearance, shaping facility, and reasonable costs, the Medium-Density Fiberboard (MDF) is a material that is much appreciated by architects, designers, or those responsible for museum exhibitions, and for such reasons, its use is sometimes difficult to avoid, even in the airtight display cases. There are commercial types of MDF graded as low-emitting or even formaldehyde-free; they are more costly than normal MDF and cannot be a priori recommended, because in many cases, they failed to pass the standard corrosion museum tests.

The diffusion of modern synthetic materials with their different compositions and commercial formulations increased enormously the number of organic compounds that 
can be found in the indoor museum environment, particularly within enclosures. In the construction of modern display cases, laminated glass and steel are the principal structural components, but the presence of other functional materials cannot be disregarded. There are paints or varnishes for treatments of surfaces; adhesives, elastomers for sealing, insulating rubbers or tapes; plastics, foams, and textiles for case decoration. Each one of these (organic) materials may cause trouble by giving off solvents, unreacted monomers, decomposition products, catalysts, or low-molecular weight components from a variety of additives: plasticizers, heat and light stabilizers, fire-retardants, processing aids, pigments and dyes, surfactants. A single material may emit an unexpected large number of compounds. A gas chromatographic analysis of VOCs from polymer paint may reveal up to 100 compounds, ranging from several homologous series to different chemical structures. For most of the compounds possible, noxious effects on the cultural heritage objects are not known; for others, a warning could arise by the inspection of structures and functional groups. In addition to the general agreement about the dangers of formaldehyde, formic and acetic acids, and sulfides, the multiplicity of (unknown) effects resulting from the new commercial materials and formulations is the new challenge. Carboxylic acids with carbon atom numbers higher than two are often found in VOCs emitted by organic materials and they might be, in particular cases, active in corrosion processes. Some of the negative effects of fatty acids in a sealed environment have been previously described. Acrylic and methacrylic acids are often emitted by paints and adhesives, and their danger to heritage remains to be determined. Similar attention should be devoted to aldehydes heavier than formaldehyde that by oxidation can generate the corresponding acids.

As described, organic amines from UV stabilizers have come to museums' attention in recent times [38,39], and therefore, other types and sources of amines must be carefully considered. Most of the water-based paints contain amines that become the cause of exclusion from use in display cases components. Alkylmorpholines and (N,N dimethyl) alkylamines off-gassed from polyurethane foams have been found as efflorescences on objects in museum storage [44]. On the other hand, solvent-based synthetic paints whose principal solvents are mixtures of cellosolve esters happen to bear traces of acetic acid, which is either formed in some hydrolytic decomposition of the esters or present as a residual reagent in the unrefined industrial solvent. Paints, adhesives, and plastic or rubbery materials can as well be the source of other compounds to avoid, including sulfurcontaining stabilizers or dyes and halogenated compounds from fire retardants or from polymer decomposition. All types of silicone adhesives and sealants emit not negligible quantities of cyclic siloxanes formed by four to six repeating units and are key starting structures for the synthesis of silicone rubbers and resins; they are quite volatile, and it is common to find them in many indoor environments. Siloxanes are often also included in aqueous polymer dispersions as anti-foam additives. As there are no reports of concern with respect to artworks, they are considered safe. Their high release and permanence in aquatic and air environment has attracted the attention of European authorities, and in the near future, it is expected that a restriction on the presence of the cyclic tetrasiloxane (the more volatile) will be issued [45].

With the widespread use of new materials and the recognition of the continuous changes occurring in industrial formulations, in some instances forced by eco- and humantoxic concerns, the term "emerging indoor pollutants" has been raised for some time now in environmental science [46]. Emerging pollutants may be new chemicals or chemicals whose hazardous nature has been reassessed, and also chemicals that can be now better identified in indoor areas thanks to the high sensitivity of modern techniques. The definition perfectly applies to the cultural heritage domain, where an advance of knowledge is necessary about indoor VOCs, their effects on museum collections, and affordable techniques for their measurements. 


\section{Which Pollutant Levels for Artifacts Deterioration}

There is no way at present of defining acceptable levels of pollutants with respect to the protection of artworks and artifacts. In the museum environment, in particular, it is difficult to establish when a corrosion process starts and what is the influence of the existing mixture of pollutants. The same pollutant may produce different corrosion effects depending on object composition, porosity, or surface treatments. The levels of gaseous pollutants associated with damages to different substrates that can be found in the literature are until now concentrated on the main carbonyl recognized pollutants, i.e., formic and acetic acids, formaldehyde and, in some instances, acetaldehyde as well. The interest for museums has been concentrating on the comparison between outdoor and indoor concentrations, differences between galleries and more secluded exhibition rooms, and situations within enclosures and display cases [3]. Significant examples concerning the investigation methodology and the results obtained are described below.

An extensive survey of carbonyl pollutant concentrations was performed on different selected sites in British and Dutch museums, looking at storage and display cabinets where artifact deterioration was present [47]. Most of the cabinets, used for decades, were made of natural woods; more recent enclosures had a combination of woods, synthetic composites, adhesives, and varnishes. The study could be done on a relevant number of sites in collections holding archaeological, decorative art, and natural history specimens. The survey verified that acetic acid was usually predominant over the other carbonyl pollutants, with exceptions where differences were tentatively justified by the presence of different materials or different types of wood. From the monitoring at different museum sites, concentration ranges for each of the four main pollutants (two acids and two aldehydes) could be obtained, which is useful for correlation with the type of enclosure and the presence of unsuitable materials. The concentrations of interest for carbonyl pollutants are in the $\mathrm{ppb}$ range and were established to vary in the order: galleries $<$ storage areas $<$ display cases and storage cabinets. However, a strict relationship between concentrations of the various carbonyl pollutants in cabinets and the resultant composition of the corrosion products could not be established, thus confirming the difficulty of understanding the chemical interactions between artifacts and carbonyl pollutants in the real museum environment with different pollutants and different competing substrates apt to react.

The type of monitoring described above may be used to qualify (or check) the indoor environment in selected museum rooms or enclosures but gives no information about the minimum allowed concentrations for inducing corrosion on the objects. To gain real understanding of the effects of a pollutant on specific materials, laboratory experiments must be planned where concentrations, chemical compositions, exposition time, and other conditions can be carefully controlled. Few such studies have been reported until now, one of the reasons being that to simulate real exposure conditions, long data collection times are required.

In one study, the tendency of lead to corrode over the period of one year in the presence of acetic acid vapors has been determined [48]. Corrosion sensitivity was investigated under varying acetic acid concentrations, exposure durations, and RH. The time development of corrosion was followed by means of different instrumental techniques, but essentially, the weight gain of lead coupons was used for quantitation. The results showed that even in the simplified model situation with only one metal and one pollutant, the corrosion process depends on complex electrochemical and physicochemical contributions where, in addition to the nature and amount of the pollutant, relative humidity and the composition and morphology of the lead and its surface matter. The nature of corrosion products was strongly influenced by RH levels. Tarnished lead samples had a better corrosion resistance than untarnished ones, indicating some passivation of the surface. Over a period of 12 months and with RH levels below $75 \%$, no damage was detected on lead samples at acetic acid concentrations below $0.43 \mathrm{mg} \mathrm{m}^{-3}$, but considering that other volatile carbonyl compounds may be present in display or storage enclosures, the recommendation for lead conservation was to maintain the acetic acid or total carbonyl compounds concentration 
in the enclosures below $0.1 \mathrm{mg} \mathrm{m}^{-3}$. It was also suggested that if the level cannot be maintained at such values, a way to minimize the corrosion rate is to reduce the RH in the enclosures.

The same type of approach was used for studying the tendency of copper and lead to corrode in closed environments containing formic acid alone or mixtures of formaldehyde, formic, and acetic acids [49]. Copper was seen to react mainly with formic acid, while lead reacted with the two acids in a more complex way. Lead acetate compounds formed thick corrosion layers, which are quite different in aspect from the lead formate compounds. The formate films on the lead surface were able to inhibit the acetic acid action. No contribution of formaldehyde to the corrosion process was observed on the two metals, which was explained by the absence in the atmosphere of oxidants for the transformation into formic acid. The minimum concentration levels for detecting corrosion effects were practically in the same range of the previous study, with a reactivity limit of formic acid on lead below $0.1 \mathrm{ppm}\left(0.1 \mathrm{ppm}\right.$ formic acid $\left.=0.19 \mathrm{mg} \mathrm{m}^{-3}\right)$.

Additional research is needed to better define acceptable levels of carboxylic acids and aldehydes with respect to the protection of artworks and artifacts. In any case, it is agreed that the pollutant limit for indoor air quality in museums is in the ppb (or $\mathrm{g} \mathrm{m}^{-3}$ ) range. In the Grzywacz fundamental book on monitoring gaseous pollutants [50], the table in Appendix 2 shows numbers indicating that for most sensitive materials, pollutant levels of acids should be less than $5 \mathrm{ppb}$, and there should be even lower values for formaldehyde.

In the future, it will be necessary to obtain sensitivity data on the effects of the new compounds we have seen appear in the emissions of synthetic materials. For example, in public libraries, aldehydes other than formaldehyde are often found, with indoor levels significantly higher than outdoor, ranging from few tens to several hundred $\mathrm{g} \mathrm{m}^{-3}$ [51]. The origin is from the indoor materials, furniture, and paints, and in an environment with such complexity of materials, the aldehyde oxidation to acids has great chances of taking place. Moreover, in libraries and archives, the contribution from paper degradation to volatile emissions cannot be disregarded [52]. In museums, the diffusion of the new materials (plastics and rubbers, paints, adhesives) used for storage containers and display case components has enormously increased the number and types of chemical compounds emitted in the indoor spaces [53-55]. The measurement of pollutants in display and storage cases repeatedly showed fairly high levels of VOCs compared with much lower concentrations in galleries and rooms. For most of the new volatile compounds detected in those indoor environments, it is not even known if they are harmful to the objects, and studies on the permissible levels of these new pollutants are not available. Some compounds have already been targeted as dangerous in the museum environment for inducing corrosion or other visible effects on artworks. For example, ketoximes may be present in emissions of some neutral silicone sealants [56], and they have been recognized to react with copper and copper alloys. Chemical structures that are now under the attention of the museum's conservation community are organic amines in general, with particular attention to piperidine derivatives [38,39], the carboxylic acids with $C>4$, and the acrylic and methacrylic acids.

Once it is determined that a compound present in the air of museum enclosures is promoting damage on artifacts and experimental exposure limits are not available, it seems reasonable to indicate a priori a precautionary concentration limit of few ppb for the single compound.

When volatile organic compounds are detected and quantified, they are often grouped together under the term of total VOCs (TVOCs). According to the norms on indoor air, TVOCs is given by the sum of the concentrations of all identified and non-identified VOCs using the response factor of toluene and eluted in the gas chromatogram between n-hexane and n-hexadecane [57]. The lower carboxylic acids and formaldehyde, the most important compounds to control for cultural heritage conservation, are not included in the VOCs, similarly to higher molecular weight compounds that are often present in formulations of adhesives or other polymeric materials and that, despite their higher boiling points, 
can vaporize from materials. Therefore, a comprehensive way of looking at the overall emission from materials is by adopting subgroups: very volatile organic compounds, VVOCs with the number of carbon atoms $C<6$; VOCs with $6 \leq \mathrm{C} \leq 16$; semi-volatile organic compounds, SVOCs with C $>16$.

\section{The Evaluation of Emissions from Display Cases Materials}

The most commonly applied method by museums for testing the presence of dangerous emissions from materials is the so-called "Oddy test". The test has been developed at the British Museum [58] and adapted or modified a number of times for more reliable results [59]. It is nowadays generally agreed that the "Oddy test", basically a test for metal corrosion, is not a valid risk assessment solution in the selection of materials safe for collection objects. In a number of cases, materials validated by the test and used in the construction of display cases acted as emitters of substances that induced damages. Therefore, it is necessary to rely on more direct techniques that are capable of monitoring indoor pollutants in the given environment. The book by Grzywacz extensively describes techniques and devices for monitoring gaseous pollutants in museum environments [50]. Useful updating to recent years can be found in a report from the Swedish National Heritage Board [60]. Many, if not all, of the techniques and devices derive from applications in public or private spaces: industries, buildings, schools, etc., and the standard reference concentrations are those established for human health. Standards for indoor museum pollution do not exist, and the concentration limits for avoiding damage to artifacts are by far more stringent than those coming from health organizations. The immediate consequence is that measurement techniques and detection systems must be more sensitive (in the ppb range, otherwise expressed by $\mathrm{g} \mathrm{m}^{-3}$ units), which is not always possible with the devices available on the market. Few of them are, up to now, specifically tailored for cultural heritage, and they may not be sensitive enough to detect low pollutant concentrations.

Assessment of whether a material can be used for the construction or decoration parts in display cases must include the measurement of VOCs in order to check any outgassing that can produce damage to artifacts. As the emission process can last for a long time and accumulation can reach critical values to start corrosion or crystallizations, in an airtight display case, even an extremely low concentration of a dangerous pollutant may not be tolerable. The experience has shown that organic materials emit a large number of VOCs, and for most of them, the interactions with artwork materials are not known. Looking at their chemical structures and from general knowledge about the reactivity of functional groups, they are not harmful and can be retained and employed in showcases until new experimental evidence is produced. Given such a situation, all VOCs emitted from an examined material should be listed in a safety data sheet, which would be useful for proper re-evaluation in case of unexpected later damaging effects.

Interesting findings resulted from a detailed investigation on the emissions from a large number $(\approx 100)$ of modern materials used for the construction and decoration of display cases [61]. Under the different forms of coatings and lacquers, gaskets, fabrics, particles, and fiberboards, many types of polymeric structures were involved, from acrylics to polyurethanes, to silicone rubbers to polyesters and epoxies. All the materials showed important amounts of total VOCs, from hundreds to several thousands $\mu \mathrm{g} \mathrm{m}^{-3}$ after only $24 \mathrm{~h}$ permanence in a test chamber. As expected, wooden boards had emissions of formic and acetic acids as well as formaldehyde. Lacquers and coatings were found to emit higher amounts of VOCs compared with the wood composites; they were all solvent-based systems, and the most abundant emissions could in fact be recognized as residual solvents. It was less expected to find acetic acid in the emission products of the coatings. The more common family of solvents for polymer coatings is that of acetates, and the acetic acid was attributed to hydrolysis in ester solvent molecules. However, ester hydrolysis is not likely to occur under normal exposure conditions of coated surfaces; traces of acetic acid in the solvent mixture could be eventually explained as residual impurity from the acetate synthesis in technical grade solvents. Ethyl acetate has been reported to contain traces 
of acetic acid $(<0.5 \%)$, and the complete purification of acetate esters by the removal of impurities with distillation or other physical methods is costly, if not impossible [62].

In display cases with no active air ventilation and/or filtration examined directly after production at the manufacturer site and after different times in museum use, it could be confirmed that the modern-type showcases emit a large number of VOCs from different types of construction materials [63]. Paints and coatings in particular were responsible for high amounts of solvents and additives, with acetate compounds and their acetic acid companion. In comparison, old-type showcases constructed with traditional (wooden) materials were emitting lower amounts of VOCs but higher levels of formaldehyde, formic, and acetic acids. Higher air pollution levels in the modern-type showcases were attributed to the airtightness of the constructions with a consequent accumulation of the gaseous emissions.

From all the data so far discussed, we learn that modern materials employed for the construction of display cases should be validated firstly for the absence (which means concentration below detection limit) of compounds already known to induce damages to the artifacts: sulfur compounds, formaldehyde, the low molecular weight carboxylic acids, organic amines and piperidine compounds, oximes. As for the multitude of VOCs and SVOCs that can accumulate in the environment, a precautionary measure would be the implementation within the case of air ventilation and suitable sorbents.

A protocol for evaluating the emissions from materials of interest in museum display cases has been proposed by the Institute for Materials Research and Testing in Germany [64]. The first requirement is that the substances known to bring high risks to the cultural heritage must not be detected in the emissions from the material. Target compounds are acetic acid, formic acid, formaldehyde, oximes, isocyanates, and a piperidine derivative. Based on the current state of technology and analytical procedures, individual threshold detection limits are set for the different substances in the range $5-15 \mu \mathrm{g} \mathrm{m}^{-3}$. The requirement for VOCs is that their sum must not exceed the following values: $\Sigma$ VVOCs $100 \mu \mathrm{g} \mathrm{m}^{-3} ; \Sigma$ VOCs $500 \mu \mathrm{g} \mathrm{m}^{-3} ; \Sigma$ SVOCs $100 \mu \mathrm{g} \mathrm{m}^{-3}$. For silicone sealants, a deviating value of $2000 \mu \mathrm{g} \mathrm{m}^{-3}$ is indicated for $\Sigma$ VOCs, due to the known fact that these materials emit large quantities of cyclic siloxanes.

While the proposed procedure appears to be a useful guideline for measuring emissions from construction materials of interest, the maximum acceptable values for VOCs may be questionable in respect to a preventive conservation approach. At present, there is no evidence about the cumulative effect of VOCs on the artworks, whereas it is very possible that in some VOCs, the mixture a single compound will induce noxious effects.

A convenient procedure for measuring emissions from the construction materials of interest for museum showcases is by sampling the VOCs with solid-phase micro-extraction (SPME) followed by thermal desorption and gas chromatography/mass spectrometry for the separation and identification of the chemical compounds. SPME sampling is made by head-space extraction on silica fibers coated with a sorbent [65] and is a fast and sensitive technique. Several headspace-SPME-GC/MS methods have been developed for materials studies and cultural heritage applications.

Solid-phase micro-extraction (SPME) was used for measuring emissions of acetic and formic acids from materials used in drawers or shelves in a museum [66]. Active air sampling was possible using much smaller air volumes than traditional laboratory-based chamber studies, thus making it possible to make concentration measurements in small airtight volumes as found in display cases, cabinets, and storage boxes.

SPME coupled to gas chromatography/mass spectrometry (GC/MS) was applied for characterization of the volatile organic compounds emitted from a naturally aged old book in order to identify markers of aged paper and gain better knowledge of the smell-causing volatile compounds from the book [67]. Two different sampling methods were successfully developed and compared: headspace SPME and contact SPME, the latter one being of great interest for measurements on cultural heritage objects, as it is non-destructive. Semivolatile organic pesticides emitted from museum objects could be easily identified with SPME sampling [68], and in another study, the identification of an archaeological glue 
was made possible by SPME sampling of the emissions from birch bark tars [69]. The same technique was applied to identify the volatile compounds sampled in a museum showcase containing a wax sculpture [70]. The use of beeswax in the sculpture could be unequivocally confirmed by the presence of characteristic molecular compounds. In another study, SPME and GC/MS were employed to determine the total volatile organic compounds (TVOCs) contents in textiles [71], demonstrating that the technique was useful for measuring emissions also in non-uniform materials. A study on VOCs emitted from standard plastic materials was developed with SPME-GC/MS in order to find specific marker compounds for identification of the plastics. Emissions from museum objects were subsequently characterized, with attention to the volatile compounds deriving from the natural aging of polymeric matrices [72].

Another application of the technique was intended to detect the activity of molds on historical objects [73]. Selected fungal species already isolated from historic objects were inoculated on model samples of materials of interest (paper, wool, silk, parchment), and the VOCs formed after a few days could be sampled by SPME and analyzed by GC-MS. The results were in support of the hypothesis that the metabolic activity of molds growing on materials of historical interest can be traced based on the detection of specific groups of volatiles.

The potential of SPME as a portable and easy-to-operate sampling technique in museums is demonstrated in a study for identifying VOCs responsible of efflorescence on objects within exhibition cases [74]. The proposed SPME sampling protocol is appealing to conservators, allowing them to receive and expose the SPME fibers in the display case without the intervention of a scientist. After sampling, the fibers were easily shipped to the laboratory for analysis. It was also suggested that the rapid detection of volatiles from case interiors is functional to the control of the efficacy of mitigation strategies used in the display cases to reduce the VOCs accumulated. In air-tight cases holding different types of ethnographical objects, SPME measurement of VOCs was used to identify the cause of the strong smell perceived by the staff when opening the cases [75]. The fiber sampling lasted for a 24-h exposure time and could be performed both headspace and with direct contact on the objects without any disturbance of the ongoing exhibition nor visually interfering with museum visitors.

Therefore, the multiple appeals of the SPME technique are as follows: fast, not invasive, easy sampling in situ or in contact with an object's surface, and sensitive enough, with detection limits that can reach very low values $<1 \mu \mathrm{g} \mathrm{m}^{-3}$. With some ad hoc experimental arrangements, quantitative data have been obtained that compare well with standard indoor air quality (IAQ) detection methods [66,76].

VOCs emitted from materials of interest in the field of cultural heritage are also investigated by collecting volatiles with sampling tubes that subsequently go to a thermal desorption system coupled to GC/MS. Sampling can be made in situ or in the laboratory, and the method is in some way comparable to SPME. VOCs and SVOCs from new materials provide useful characterization data and allow the identification of harmful compounds; while analysis of compounds sampled from aged objects gives information about ongoing degradation processes [77].

Another method for the assessment of low molecular weight compounds in materials that in a closed environment become gaseous emissions is the particular thermal desorption technique called Evolved Gas Analysis (EGA). In EGA, milligram quantities of a sample in a furnace or a pyrolysis chamber are heated for a selected time, from seconds to few minutes at high temperature, below the material decomposition. VOCs and SVOCs are immediately desorbed from the sample and directly transferred to the GC/MS for separation and identification [78]. The technique is simple and relatively fast. It should be considered micro-invasive, but the small amounts required make EGA are in some instances suitable to investigate cultural heritage objects. Application to plastic samples commonly used in museum constructions gave results comparing well with those obtained with more traditional techniques [79]. 
All the results and reports available on the gaseous compounds that can be emitted by the modern construction materials make it clear that from the point of view of heritage conservation, the traditional Oddy test is not sufficient to assess suitability for use in display cases or storage containers or boxes and other enclosures, and that it is becoming necessary to look at all the VOCs and SVOCs emitted by materials, trying to understand if some of the compounds may be harmful to objects in the museum. It is also more and more widely acknowledged that in addition to failing the recognition of substances safe to metals but capable of noxiously interacting with other type of materials, the Oddy test takes too long to accomplish; however, for its apparent facility and low cost, it is, and for quite some time will continue to be, a preferred technique by museum staff. It has been proposed that for a given material, the volatiles analyzed by GC-MS could be evaluated in relation to the Oddy test performance, implying that the emissions from a material approved in the test will be safe in the museum environment. As already illustrated, a similar result cannot guarantee the absence of dangerous compounds [80].

\section{Removal and Control of Emissions}

Any construction material of organic origin introduced in a museum environment is a potential carrier of volatile and semi-volatile compounds that are capable of harming heritage artifacts. As far as modern display cases are considered, construction characteristics and materials involved are such that emission-free display cases are not possible, and indeed, we must refer to low-emission showcases. Constructors and the conservation community in museums are aware that with new installations, the necessity arises of an adequate maturing of the enclosures, which should be kept completely open in well-ventilated spaces to allow for the outgassing of VOCs and SVOCs. Time constraints most often make it unfeasible to properly season the enclosures, or else the time for complete outgassing of the low molecular weight compounds contained in the materials is extremely long (months) to fulfill. Moreover, in the showcases, the contribution of volatiles emitted by the exhibited objects must be considered. This implies that in airtight modern display cases, VOCs and SVOCs originating either from objects therein contained or from some construction material can accumulate in the indoor air until they eventually reach troublesome concentrations. Therefore, the way for air cleaning in museum enclosures is the use of suitable adsorbents.

Adsorbents for pollutants reduction have been used for a long time, and interested readers may refer to the existing specific literature for the general aspects of production, physical characteristics, and working mechanisms. What is worth mentioning here is that adsorbents in cultural heritage environments must be highly efficient, commercially accessible, and affordable. An excellent report on the types, structures and general properties of adsorbents for pollution reduction in cultural heritage collections was produced at the Swedish National Heritage Board [81]. The adsorbents most used are activated carbons, activated alumina, silica gel, zeolites and, more recently, polymer-based substrates. Their performance against target molecules to adsorb depends on the overall physical properties of the porous substrate and the working environment. Within display cases, the adsorbents efficiency for the reduction of pollutants is strongly dependent on whether the system works in passive or active mode. In passive mode, there is no forced air circulation in the enclosure, and adsorption rates are obviously slower than in active mode, where air is forced through the adsorbent material. The air flow in the display case can be operated continuously or at selected intervals for fixed times, and this indoor air recirculation constitutes a multi-pass filtration.

The behavior of different types of adsorbents for the removal of air pollutants from museum display cases has been the subject of specific investigations. Most of the comparisons are between activated carbons and activated alumina, and the principal target molecules are formic and acetic acids and formaldehyde with, in some cases, the inclusion of major atmospheric pollutants [82]. Laboratory results in general point out that activated carbon materials perform better than other substrates for the adsorption capacity against 
a wide range of adsorbates, with some zeolites occasionally competing with carbon materials for interaction with acetic acid [83,84]. The efficacy of a set of carbon materials for reducing the concentration of formic and acetic acids has been investigated under real museum conditions by installing the adsorbents on different showcases containing heritage objects [85]. The reduction of acid concentration could be obtained in all the showcases but at different extents depending on the type of carbon material, pure or impregnated granulate, carbon-coated foam, or activated carbon cloth. Carbon cloth and carbon-coated foam were more effective than granulate. For the different adsorbents, the efficiency in acid reduction was also strongly influenced by the air exchange rate of the showcase, and under favorable conditions, some adsorbents could reduce the acids concentration below the recommended target level.

The efficiency for acetic acid adsorption of different types of commercial materials (activated carbon, activated alumina, zeolite, two bentonites) has been also studied by measuring the corrosion rates on lead probes [86]. All the sorbents were considered applicable for the sorption of low concentrations of acetic acid vapors in museum depositary environments. The physical characteristics of the porous adsorbents were also determined to find correlations with the protection efficiency. The most effective adsorbents of acetic acid vapors turned out to be the activated alumina and the activated carbon, which were the materials with the largest specific surface areas.

Acetic and formic acids are again the target molecules in a study about the capacity of carbon adsorbents to efficiently remove excess organic acids in museum storage rooms [87]. The interest was about measurements made in situ in two different real spaces: a storage of historical books and a storage containing mixed materials, from archaeological waterlogged wood to modern plastics. Two cartridge filters with carbon adsorbents were tested, having different air cleaning characteristics. The removal efficiency of the two filters was found to be strongly influenced by air flow conditions, and the benefits from active air filtration in rooms could not be confirmed for the operating conditions.

In a recent systematic study dedicated to adsorbents for the removal of museum pollutants, the filtration efficiency of 37 different adsorbent media has been assessed under conditions simulating active and passive (with and without forced air exchange) display cases [88]. Adsorbents comprised activated carbons with and without impregnation, activated carbon cloths and carbon-coated foams, natural and synthetic zeolites, molecular sieves, silica gels, archival cardboards, polymer-impregnated matrixes, and others. Efficiency of the adsorbents was determined from the achieved concentration reductions of selected target substances under the active or passive mode of operation. Target substances were the usual main harmful compounds in the museum environment: formaldehyde, formic, and acetic acid to which toluene and alpha-pinene were added as representative of the many VOCs detected in museum enclosures. From the overall extensive testing, a confirmation comes that pure and impregnated activated carbons have the best adsorption efficiency against the selected target substances. One surprising result was that in the passive mode, nearly all adsorbent media showed performances better than those under active conditions. The possible explanation is that under the test experimental conditions, in the passive mode, the residence time of pollutants with the adsorbents is longer than in the active mode. With high air exchange rates, the reduction of pollutants turned out to be lower than that occurring at lower air rates. Apparently, this consideration seems to favor passive adsorbent installations in display cases, but it must be considered that the active mode results have been obtained with only one pass through the filter unit, whereas in museum display cases, filtration devices will recirculate the air many times during operation.

An interesting finding was also that commercial materials specially designed for museum applications were not well performing or even performed badly.

In the conservation community, there is growing agreement about considering carbonbased materials the best choice for the control of pollutants in the museum environment. The critical point can eventually be what type of carbon sorbent should be selected between 
the many commercial options. The results above described are in some way comforting, as they point to the general good performance of different types of carbon sorbents. Therefore, primary choice criteria can become the cost of the material and handling facility.

While research on indoor air quality and on the role of modern materials are strongly growing, it cannot be disregarded that new types of adsorbents are constantly under development, and new suggestions may come for the heritage wellness. Examples of new materials for the removal of indoor air pollutants in museums concern optimized mesoporous silica [89] and metal-organic framework (MOF) structures tailored for the adsorption of low concentrations of acetic acid [90].

It appears evident that in modern museum display cases, the ventilation with air flowing through active sorbent material will be often necessary to maintain acceptable concentration levels of the gaseous products emitted by construction materials and by the exhibited artifacts. A comprehensive preventive conservation scheme implying active air circulation within the showcase and through functional sorbent materials has been proposed for the complete suppression of emitted compounds [91]. For monitoring the filtration efficacy in the display case, an affordable system by direct SPME sampling in the air flow has been developed. Moreover, a continuous monitoring of the air quality within the showcase was done by the insertion of a photoionization detector that is capable of measuring VOCs in the air. The system is not selective, as it gives the total VOC concentration, with $\mathrm{ppb}$ sensitivity. In addition, it includes temperature and humidity sensors, making the whole a useful instrument for the display case environment control.

\section{Conclusions and Recommendations}

Museum display cases are tools for the protection and preservation of our cultural heritage allowing, at the same time, an excellent view of the objects inside. Over the last 10-20 years, modern display cases changed from being simple glass enclosures to technological machines for preventive conservation. In addition, they offer shielding from dust and external pollutants while maintaining a stable indoor environment by controlling temperature and relative humidity values. Airtightness can favor the accumulation of indoor-generated pollutants, and this fact must be consequently taken into account. The selection of construction materials for the display cases becomes a crucial point, and requirements are becoming more and more demanding: not only can wood-based materials not be accepted because they are the main emitters of corrosive acidic compounds, but many of the organic-based modern materials employed as adhesives, paints, coatings, sealants, and insulators must be carefully checked prior to being approved for use because they emit a broad variety of volatile organic compounds we do not know enough about. Being recognized that it is impossible to have an emission-free display case, it is necessary to refer to "low-emissions" display cases.

More research and technological improvements are needed on materials and systems of museum interest for an effective cultural heritage preventive conservation approach. In particular, the research should be focused on construction materials, adsorbents for pollutants removal, and active sensors.

The usual empirical corrosion tests employed in museums are no longer sufficient to validate the construction materials, and complete identification of the VOCs and SVOCS is required for a more solid rating. Sampling and laboratory identification techniques appear to be sensitive enough for the task. Portable devices for the in situ rapid detection of volatiles from the display case interior would be an effective advancement. They can allow rapid control of the efficiency of the adsorbents in the display case. High-sensitivity sensors, specific for the families of compounds harmful to the artifacts, should be developed for insertion in the showcases, with networking capability for data acquisition and wireless communication. An array of sensors in the showcase would be functional for actuating fans and air flow through filtration units. As it may be appreciated, the validation of low-emission display cases is a challenging task. 
The actual knowledge of the compounds that in a sealed environment cause damage to artifacts can be used by the constructors of showcases and other enclosures, and in general by the conservation community, for inducing suppliers of raw materials at the production of "museum grade" paints, adhesives, sealants, and others. For example, the solvent-based paints and coatings should be formulated without acetate ester or cellosolve type solvents, in order to avoid the traces of acetic acid deriving from the synthesis or from hydrolysis. Similarly, the water-based paint formulations should be absolutely free from organic amines used for latex stabilization and from any of the sulfur-containing additives added as antioxidants. Producers of adhesives or rubbery materials should be asked to exclude from their polymeric formulations the UV stabilizers containing amine derivatives and sulfur compounds, which are not necessary for the indoor museum applications. Museum-grade materials would be a real benefit for the artwork's preservation and a title of merit for the producing companies caring for the world cultural heritage.

To conclude this survey on indoor air quality in museum display cases, a comment on airtightness can be added, in the awareness that less stringent requirements on the air-exchange rate greatly reduce the effects of pollutants on displayed objects. In a viable decision-making approach, the comparison of risks from a leaky case or from indoor generated gaseous pollutants should be considered by the museum responsible.

Author Contributions: Conceptualization, O.C. and T.P.; writing-original draft preparation, O.C. and T.P.; writing-review and editing, O.C. and T.P. All authors have read and agreed to the published version of this manuscript.

Funding: This research received no external funding.

Conflicts of Interest: The authors declare no conflict of interest.

\section{References}

1. Salthammer, T. Emissions of Volatile Organic Compounds from Products and Materials in Indoor Environments. In Indoor Air Pollution; The Handbook of Environmental Chemistry; Pluschke, P., Ed.; Springer: Berlin/Heidelberg, Germany, 2004; Volume 4F, pp. 37-71.

2. Uhde, E.; Salthammer, T. Impact of Reaction Products from Building Materials and Furnishings on Indoor Air Quality-A Review of Recent Advances in Indoor Chemistry. Atmos. Environ. 2007, 41, 3111-3128. [CrossRef]

3. Hatchfield, P.B. Pollutants In The Museum Environment: Practical Strategies For Problem Solving. In Design, Exhibition and Storage; Archetype Publications: London, UK, 2002.

4. Toby, R.; Burke, M. A set of conservation guidelines for exhibitions. In Objects Specialty Group Postprints; The American Institute for Conservation of Historic \& Artistic Works: Washington, DC, USA, 2000; Volume 7, pp. 5-20.

5. Cassar, M.; Martin, G. The environmental performance of museum display cases. Stud. Conserv. 1994, 39 (Suppl. 2), 171-173. [CrossRef]

6. Watts, S.; Crombie, D.; Jones, S.; Yates, S. Museum showcases: Specification and reality, costs and benefits. In Museum Microclimates; Padfield, T., Borchersen, K., Eds.; National Museum of Denmark: København K, Denmark, 2007; ISBN 978-87-7602-080-4.

7. Tétreault, J. Airborne Pollutants in Museums, Galleries and Archives; Canadian Conservation Institute: Ottawa, ON, Canada, 2003.

8. World Health Organization. "Indoor Air Quality: Organic pollutants." Report on a WHO Meeting, Berlin, 23-27 August 1987. 1989. Available online: https://www.worldcat.org/title/indoor-air-quality-organic-pollutants-report-on-a-who-meeting-berlinwest-23-27-august-1987/oclc/21598714 (accessed on 8 March 2021).

9. Tennent, N.H.; Baird, T. The deterioration of Mollusca collections: Identification of shell efflorescence. Stud. Conserv. 1985, 30, 73-85.

10. Salem, M.; Bohm, M. Understanding of Formaldehyde emissions in solid wood: An overview. BioResources 2013, 8, 4775-4790. [CrossRef]

11. Tennent, N.H.; Baird, T. The identification of acetate efflorescences on bronze antiquities stored in wooden cabinets. Conservator 1992, 16, 39-47. [CrossRef]

12. Tennent, N.H.; Tate, J.; Cannon, L. The corrosion of lead artifacts in wooden storage cabinets. SSCR J. 1993, 4, 8-11.

13. Thickett, D.; Bradley, S.; Lee, L. Assessment of the Risks to Metal Artifacts Posed by Volatile Carbonyl Pollutants; Mourey, W., Robbiola, L., Eds.; James and James (Science Publishers) Ltd.: London, UK, 1998; pp. 260-264.

14. Boccia Paterakis, A. The Influence of Conservation Treatments and Environmental Storage Factors on Corrosion of Copper Alloys in the Ancient Athenian Agora. J. Am. Inst. Conserv. 2003, 42, 313-339. [CrossRef]

15. FitzHugh, E.W.; Gettens, R.J. Calclacite and Other Efflorescent Salts on Objects Stored in Wooden Museum, Cases; Science and Archaeology; Brill, R.H., Ed.; The MIT Press: Cambridge, MA, USA, 1971; pp. 91-102. 
16. Gibson, L.T.; Cooksey, B.G.; Littlejohn, D.; Tennent, N.H. Investigation of the composition of a unique efflorescence on calcareous museum artifacts. Anal. Chim. Acta 1997, 337, 253-264. [CrossRef]

17. Segan Wheeler, G.; Wypyski, M.T. An unusual efflorescence on Greek ceramics. Stud. Conserv. 1993, 38, 55-62.

18. Halsberghe, L.; Gibson, L.T.; Erhardt, D. A collection of ceramics damaged by acetate salts: Conservation and investigation into the causes. In Proceedings of the 14th Triennial Meeting, The Hague, The Netherlands, 12-16 September 2005; pp. 131-138.

19. Linnow, K.; Halsberghe, L.; Steiger, M. Analysis of calcium acetate efflorescences formed on ceramic tiles in a museum environment. J. Cult. Herit. 2007, 8, 44-52. [CrossRef]

20. Costa Pessoa, J.C.; Antunes, J.L.F.; Figueiredo, M.O.; Fortes, M.A. Removal and analysis of soluble salts from ancient tiles. Stud. Conserv. 1996, 41, 153-160.

21. Bettea, S.; Eggert, G.; Fischer, A.; Stelzner, J.; Dinnebier, R.E. Characterization of a new efflorescence salt on calcareous historic objects stored in wood cabinets: Ca2(CH3COO)(HCOO)(NO3)2·4H2O. Corros. Sci. 2018, 132, 68-78. [CrossRef]

22. Gibson, L.T.; Watt, C.M. Acetic and formic acids emitted from wood samples and their effect on selected materials in museum environments. Corros. Sci. 2010, 52, 172-178. [CrossRef]

23. Podany, J. Corrosion of Metal Artifacts and Works of Art in Museum and Collection Environments. In ASM Handbook, Volume 13C: Corrosion: Environments and Industries; Cramer, S.D., Covino, B.S., Eds.; ASM International: Materials Park, OH, USA, 2006; pp. 279-288.

24. Selwyn, L. Metals and Corrosion: A Handbook for the Conservation Professional; Canadian Conservation Institute: Ottawa, ON, Canada, 2004; ISBN 0662379845.

25. Lykiardopoulou-Petrou, M. The Museum Environment and its Effect on Coins (Storage and Display Materials: Problems and Solutions at The Numismatic Museum of Athens). Available online: www.icomon.org (accessed on 8 March 2021).

26. Al-Malaika, S.; Axtell, F.; Rothon, R.; Gilbert, M. Additives for Plastics, 8th ed.; Brydson's Plastics Materials; ButterworthHeinemann: Oxford, UK, 2017; Chapter 7; pp. 127-168.

27. Costa, V. The deterioration of silver alloys and some aspects of their conservation. Rev. Conserv. 2001, 2, 19-35. [CrossRef]

28. Sease, C.; Selwyn, L.S.; Zubiate, S.; Bowers, D.F.; Atkins, D.R. Problems with coated silver: Whisker formation and possible filiform corrosion. Stud. Conserv. 1997, 42, 1-10.

29. Koob, S.P.; Astrid, R.; van Giffen, N.; Kunicki-Goldfinger, J.J.; Brill, R.H. Caring for Glass Collections: The Importance of Maintaining Environmental Controls. Stud. Conserv. 2018, 63, 146-150. [CrossRef]

30. Verhaar, G.; van Bommel, M.R.; Tennent, N.H. Weeping Glass: The Identification of Ionic Species on the Surface of Vessel Glass Using Ion Chromatography. In Recent Advances in Glass and Ceramics Conservation; Roemich, H., Fair, L., Eds.; ICOM Committee for Conservation: Paris, France, 2016; pp. 123-133.

31. Miles C., E. Wood coatings for display and storage cases. Stud. Conserv. 1986, 31, 114-124.

32. Choosing New Display Cases, Museum Galleries Scotland. Available online: www.museumsgalleriesscotland.org.uk/advice/ collections / choosing-new-display-cases/ (accessed on 5 January 2021).

33. Ganiaris, H.; Readman, J. Hazing on Display Case Glass: A Review and Progress on Prevention. Paper presented at the Indoor Air Quality in Heritage and Historic Environments. In Proceedings of the 12th International Conference, Birmingham, UK, 3-4 March 2016; Available online: http:/ / www.iaq.dk/iap/iaq2016/Ganiaris_IAQ2016.pdf (accessed on 5 January 2021).

34. Poulin, J.; Coxon, H.; Anema, J.R.; Helwig KCorbeil, M. Investigation of Fogging on Glass Display Cases at the Royal Ontario Museum. Stud. Conserv. 2020, 65, 1-13. [CrossRef]

35. Schilling, M.; Carson, D.; Khanjian, H. Gas chromatographic determination of the fatty acid and glycerol content of lipids IV. Evaporation of fatty acids and the formation of ghost images by framed oil paintings. In Preprints of 12th Triennial Meeting of ICOM Committee for Conservation, Lyon, France, 29 August-3 September 1999; ICOM James and James: London, UK, 1999 ; pp. $242-247$.

36. Ordonez, E.; Twilley, J. Clarifying the Haze Efflorescence on Works of Art; Analytical Chemistry News \& Features, American Chemical Society: Washington, USA, 1997; pp. 416A-422A.

37. Grøntoft, T.; Schmidbauer, N.; Wisthaler, A.; Mikoviny, T.; Eichler, P.; Müller, M.; Hackney, S. A Sommer Larsen, Voc Emissions from Canvas and Acetic Acid Deposition to Canvas and Glass. Available online: http://www.morana-rtd.com/epreservationscience/2014/ePS_2014_a4_Grontoft.pdf (accessed on 8 March 2021).

38. Newman, R.; Derrick, M.; Byrne, E.; Tan, M.; Chiantore, O.; Poli, T.; Riedo, C. Strange Events Inside Display Cases at the Museum of Fine Arts, Boston, and Lessons To Be Learned From Them-Part 1. In Conservation and Exhibition Planning: Material Testing for Design, Display, and Packing; Abstracts, Page 11; Lunder Conservation Center: Washington, DC, USA, 2015; Available online: https: / / aiccm.org.au/wp-content/uploads/2020/01/materialtestingconference-2015-abstractbooklet2FEA0168725A.pdf? (accessed on 5 January 2021).

39. Van Iperen, J.; van Keulen, H.; Keune, K.; Abdulah, K.; Van Langh, R. Crystalline Deposits in New Display Cases at the Rijksmuseum: Characterisation and Origin. Available online: https://www.tandfonline.com/doi/full/10.1080/00393630.2020.18 11475? scroll=top\&needAccess=true (accessed on 8 March 2021).

40. Krupińsk, B.; Van Grieken, R.; De Wael, K. Air quality monitoring in a museum for preventive conservation: Results of a three-year study in the Plantin-Moretus Museum in Antwerp, Belgium. Microchem. J. 2013, 110, 350-360. [CrossRef]

41. Korenberg, C.; Bertolotti, G. Emissions from MDF: Governing Factors and Mitigation Strategies. Stud. Conserv. 2019, 64, 249-260. [CrossRef] 
42. Hatchfield, P. Jane Carpenter, Formaldehyde: How Great is the Danger to Museum Collections? Harvard University Art Museums; Center for Conservation and Technical Studies: Cambridge, MA, USA, 1987; ISBN 0-916724-64. Available online: https: / / www.researchgate.net/publication/311722319 (accessed on 6 January 2021).

43. Salthammer, T.; Mentese, S.; Marutzky, R. Formaldehyde in the Indoor Environment. Chem. Rev. 2010, 110, $2536-2572$. [CrossRef] [PubMed]

44. Tsukada, M.; Rizzo, A.; Granzotto, C. A new strategy for assessing off-gassing from museum materials: Air sampling in oddy test vessels. Am. Inst. Conserv. Historic. Artistic. Works 2012, 37, 1-7.

45. European Chemicals Agency. Annex Xv Restriction Report-Proposal for a Restriction. Available online: https://echa.europa. eu/documents/10162/039f5415-d7a2-b279-d270-0d07e18f6392 (accessed on 8 March 2021).

46. Salthammer, T. Emerging indoor pollutants. Int. J. Hyg. Environ. Health 2020, 224, 113423. [CrossRef]

47. Grzywacz, C.M.; Tennent, N.H. Pollution monitoring in storage and display cabinets: Carbonyl pollutant levels in relation to artifact deterioration. Stud. Conserv. 1994, 39, 164-170. [CrossRef]

48. Tétreault, J.; Sirois, J.; Stamatopoulou, E. Studies of lead corrosion in acetic acid environments. Stud. Conserv. 1998, 43, 17-32.

49. Tétreault, J.; Cano, E.; Van Bommel, M.; Scott, D.; Dennis, M.; Barthés-Labrousse, M.; Minel, L.; Robbiola, L. Corrosion of Copper and Lead by Formaldehyde, Formic and Acetic Acid Vapours. Stud. Conserv. 2003, 48, 237-250. [CrossRef]

50. Grzywacz, C.M. Monitoring for Gaseous Pollutants in Museum Environments; The Getty Conservation Institute: Los Angeles, CA, USA, 2006.

51. Kim, J.; Kim, S.; Lee, K.; Yoon, D.; Lee, J.; Ju, D. Indoor aldehydes concentration and emission rate of formaldehyde in libraries and private reading rooms. Atmos. Environ. 2013, 71, 1-6. [CrossRef]

52. Cincinelli, A.; Martellini, T.; Amore, A.; Dei, L.; Marrazza, G.; Carretti, E.; Belosi, F.; Ravegnani, F.; Leva, P. Measurement of volatile organic compounds (VOCs) in libraries and archives in Florence (Italy). Sci. Total Environ. 2016, 572, 333-339. [CrossRef]

53. Blades, N. A Study of the Lesser Known Pollutants: Volatile Organic Compounds in Display Cases. Indoor Air Pollution: Detection and Mitigation of Carbonyls. Available online: http:/ /iaq.dk/iap/iap1998/1998_14.htm (accessed on 5 January 2021).

54. Blades, N. Measuring Pollution in the Museum Environment. Available online: http://www.vam.ac.uk/content/journals/ conservation-journal/issue-14/measuring-pollution-in-the-museum-environment/ (accessed on 8 March 2021).

55. Larkin, N.; Blades, N.; Makridou, E. Investigation of volatile organic compounds associated with polyethylene and polypropylene containers used for conservation storage. Conservator 2000, 24, 41-51. [CrossRef]

56. Klewicz, K.; Marć, M.; Zabiegała, B. Emission profile of butan-2-one oxime from commercially available neutral silicone sealant. Microchem. J. 2020, 156, 104982. [CrossRef]

57. ISO. 16000. Indoor Air-Part 6: Determination of Volatile Organic Compounds in Indoor and Test Chamber Air by Active Sampling on Tenax TA®Sorbent, Thermal Desorption and Gas Chromatography Using MS or MS-FID. Available online: https: //www.iso.org/standard/52213.html (accessed on 8 March 2021).

58. Oddy, W.A. An Unsuspected Danger in Display. Museum J. 1973, 73, 27-28.

59. Korenberg, C.; Keable, M.; Phippard, J.; Doyle, A. Refinements Introduced in the Oddy Test Methodology. Stud. Conserv. 2018, 63, 2-12. [CrossRef]

60. Canosa, E.; Norrehed, S. Strategies for Pollutant Monitoring in Museum Environments, Swedish National Heritage Board 2019. Available online: https:/ / www.diva-portal.org/smash/get/diva2:1324224/FULLTEXT01.pdf (accessed on 5 January 2021).

61. Schieweck, A.; Salthammer, T. Emissions from Construction and Decoration Materials for Museum Showcases. Stud. Conserv. 2009, 54, 218-235. [CrossRef]

62. Anasthas, H.M.; Gaikar, V.G. Adsorption of acetic acid on ion-exchange resins in non-aqueous conditions. React. Funct. Polymers 2001, 47, 23-35. [CrossRef]

63. Schieweck, A.; Salthammer, T. Indoor air quality in passive-type museum showcases. J. Cult. Herit. 2011, 12, 205-213. [CrossRef]

64. BAM. Focus on the Low-Emissions Display Case. Description of the BEMMA Investigative and Evaluative Procedure. Available online: https: / tes.bam.de/Netzwerke/Content/DE/Downloads/Nike/bemma-procedure-2018.pdf?_blob=publicationFile (accessed on 5 January 2021).

65. Pawliszyn, J. Solid Phase Microextraction Theory and Practice; Wiley-VCH: New York, NY, USA, 1997.

66. Ryhl-Svendsen, M.; Glastrup, J. Acetic acid and formic acid concentrations in the museum environment measured by SPMEGC/MS. Atmos. Environ. 2002, 36, 3909-3916. [CrossRef]

67. Lattuati-Derieux, A.; Bonnassies-Termes, S.; Lavédrine, B. Identification of volatile organic compounds emitted by a naturally aged book using solid-phase microextraction/gaschromatography/mass spectrometry. J. Chromatogr. A 2004, 1026, 9-18. [CrossRef]

68. Ormsby, M.; Johnson, J.S.; Heald, S.; Chang, L.; Bosworth, J. Investigation of Solid Phase Microextraction Sampling for Organic Pesticide Residues on Museum Collections. Collect. Forum. 2006, 20, 1-12.

69. Regert, M.; Alexandre, V.; Thomasc, N.; Lattuati-Derieux, A. Molecular characterisation of birch bark tar by headspace solid-phase microextraction gas chromatography-mass spectrometry: A new way for identifying archaeological glues. J. Chromatogr. A 2006, 1101, 245-253. [CrossRef]

70. Lattuati-Derieux, A.; Thaoa, S.; Langlois, J.; Regert, M. First results on headspace-solid phase microextraction-gas chromatography/mass spectrometry of volatile organic compounds emitted by wax objects in museums. J. Chromatogr. A 2008, 1187, 239-249. [CrossRef] 
71. Zhu, H.; Lu, Z.; Cai, J.; Li, J.; Gao, L. Development of a headspace-SPME-GC/MS method to determine volatile organic compounds released from textiles. Polymer Test. 2009, 28, 521-527. [CrossRef]

72. Lattuati-Derieux, A.; Egasse, C.; Thao-Heu, S.; Balcar, N.; Barabant, G.; Lavédrine, B. What do plastics emit? HS-SPME-GC/MS analyses of new standard plastics and plastic objects in museum collections. J. Cult. Herit. 2013, 14, 238-247. [CrossRef]

73. Sawoszczuk, T.; Syguła-Cholewińska, J. Application of solid phase microextraction-gas chromatography-mass spectrometry method for the detection of active moulds on historical objects. Herit Sci. 2017, 5, 20. [CrossRef]

74. Alvarez-Martin, A.; George, J.; Kaplan, E.; Osmond, L.; Bright, L.; Asher Newsome, G.; Kaczkowski, R.; Vanmeert, F.; Kavich, G.; Heald, S. Identifying VOCs in exhibition cases and efflorescence on museum objects exhibited at Smithsonian's National Museum of the American Indian-New York. Herit. Sci. 2020, 8, 115. [CrossRef]

75. Alvarez-Martin, A.; McHugh, K.; Martin, C.; Kavich, G.; Kaczkowski, R. Understanding air-tight case environments at the National Museum of the American Indian (Smithsonian Institution) by SPME-GC-MS analysis. J. Cult. Herit. 2020, 44, 38-46. [CrossRef]

76. Desauziers, V.; Bourdin, D.; Mocho, P.; Plaisance, H. Innovative tools and modeling methodology for impact prediction and assessment of the contribution of materials on indoor air quality. Herit. Sci. 2015, 3, 28. [CrossRef]

77. Mitchell, G.; Catherine Higgitt Gibson, L.T. Emissions from polymeric materials: Characterised by thermal desorption-gas chromatography. Polymer Degrad. Stab. 2014, 107, 328-340. [CrossRef]

78. Schilling, M.; Learner, T. Evolved gas analysis as a tool for characterizing plastics. In Proceedings of the ICOM-CC 16th Triennial Conference, Lisbon, Portugal, 19-23 September 2011; pp. 1-11.

79. Samide, M.J.; Smith, G.D. Analysis and quantitation of volatile organic compounds emitted from plastics used in museum construction by evolved gas analysis-gas chromatography-mass spectrometry. J. Chromatogr. A 2015, 1426, 201-208. [CrossRef]

80. Samide, M.J.; Liggett, M.C.; Mill, J.; Smith, G.D. Relating volatiles analysis by GC-MS to Oddy test performance for determining the suitability of museum construction materials. Herit. Sci. 2018, 6, 47. [CrossRef]

81. Canosa, E.; Norrehed, S. Adsorbents for Pollution Reduction in Cultural Heritage Collections, Swedish National Heritage Board, Technical Report. 2019. Available online: http:/ / raa.diva-portal.org/smash/get/diva2:1368138/FULLTEXT01.pdf (accessed on 5 January 2021).

82. Grosjean, D.; Parmar, S.S. Removal of air pollutant mixtures from museum display cases. Stud. Conserv. 1991, 36, $129-141$.

83. Joao Cruz, A.; Pires, J.; Carvalho, A.P.; Brotas de Carvalho, M. Adsorption of Acetic Acid by Activated Carbons, Zeolites, and Other Adsorbent Materials Related with the Preventive Conservation of Lead Objects in Museum Showcases. J. Chem. Eng. Data 2004, 49, 725-731. [CrossRef]

84. Joao Cruz, A.; Pires, J.; Carvalho, A.P.; Brotas de Carvalho, M. Comparison of adsorbent materials for acetic acid removal in showcases. J. Cult. Heritage 2008, 9, 244-252. [CrossRef]

85. Grøntoft, T.P.; Lankester, D. Thickett. Reduction of Acidic Pollutant Gases Inside Showcases by the use of Activated Carbon Adsorbers. e-PS 2015, 12, 28-37.

86. Msallamova, S.; Kouril, M.; Charlotte Strachotova, K.; Stoulil, J.; Popova, K.; Dvorakova, P.; Lhotka, M. Protection of lead in an environment containing acetic acid vapour by using adsorbents and their characterization. Herit. Sci. 2019, 7, 76. [CrossRef]

87. Hjerrild Smedemark, S.; Ryhl-Svendsen, M.; Toftum, J. Removal of Organic Acids from Indoor Air in Museum Storage Rooms by Active and Passive Sorption Techniques. Stud. Conserv. 2020, 65, 251-261. [CrossRef]

88. Schieweck, A. Adsorbent media for the sustainable removal of organic air pollutants from museum display cases. Herit. Sci. 2020, 8, 1. [CrossRef]

89. Gibson, L.T. Mesosilica Materials and Organic Pollutant Adsorption: Part A Removal From Air. Chem. Soc. Rev. 2014, 43, 5163-5172. [CrossRef] [PubMed]

90. Dedecker, K.; Pillai, R.S.; Nouar, F.; Pires, J.; Steunou, N.; Dumas, E.; Maurin, G.; Serre, C.; Pinto, M.L. Metal-Organic Frameworks for Cultural Heritage Preservation: The Case of Acetic Acid Removal. ACS Appl. Mater. Interfaces 2018, 10, 13886-13894. [CrossRef]

91. Chiantore, O.; Riedo, C.; Poli, T.; Cotrufo, G.; Hohenstatt, P. Risk Assessment and Preservative Measures for Volatile Organic Compounds in Museum Showcases. Stud. Conserv. 2018, 63, 58-63. [CrossRef] 